\title{
Efficacy and Safety of Masitinib in Progressive Forms of Multiple Sclerosis
}

\author{
A Randomized, Phase 3, Clinical Trial
}

Patrick Vermersch, MD, PhD, Luis Brieva-Ruiz, MD, Robert J. Fox, MD, Friedemann Paul, MD, PhD, Lluis Ramio-Torrenta, MD, PhD, Matthias Schwab, MD, PhD, Alain Moussy, MEng, Colin Mansfield, PhD, Olivier Hermine, MD, PhD, and Maciej Maciejowski, MD, PhD, on behalf of the AB07002 Study Group

Neurol Neuroimmunol Neuroinflamm 2022;9:e1148. doi:10.1212/NXI.0000000000001148

\section{Abstract}

\section{Background and Objectives}

Masitinib is a selective tyrosine kinase inhibitor, targeting innate immune cells (mast cells and microglia) that are involved in the pathophysiology of progressive multiple sclerosis (MS). Study AB07002 assessed oral masitinib in patients with progressive MS who were progressing but not clinically active.

\section{Methods}

This randomized, double-blind, 2 parallel-group, placebo-controlled trial assessing 2 dose levels of masitinib vs equivalent placebo was conducted at 116 hospital clinics and specialized MS centers in 20 countries. Randomization (2:1) with minimization was performed centrally using an automated system. Patients, physicians, and outcome assessors remained masked to treatment group allocation. Patients with primary progressive MS (PPMS) or nonactive secondary progressive MS (nSPMS) without relapse for $\geq 2$ years, aged 18-75 years, with baseline Expanded Disability Status Scale (EDSS) 2.0-6.0, and regardless of time from onset were treated for 96 weeks. The primary end point was overall EDSS change from baseline using repeated measures (generalized estimating equation, timeframe W12-W96, measured every 12 weeks), with positive values indicating increased clinical deterioration. Efficacy and safety were assessed in all randomly assigned and treated patients.

\section{Results}

A total of 611 patients were randomized; 301 in the masitinib $4.5 \mathrm{mg} / \mathrm{kg} / \mathrm{d}$ parallel group and 310 in the uptitrated masitinib $6.0 \mathrm{mg} / \mathrm{kg} / \mathrm{d}$ parallel group. Masitinib $(4.5 \mathrm{mg} / \mathrm{kg} / \mathrm{d})(\mathrm{n}=199)$ showed significant benefit over placebo $(\mathrm{n}=101)$ according to the primary end point, $0.001 \mathrm{vs}$ 0.098 , respectively, with a between-group difference of -0.097 ( $97 \% \mathrm{CI}-0.192$ to -0.002$) ; p=$ 0.0256. Safety was consistent with masitinib's known profile (diarrhea, nausea, rash, and hematologic events), with no elevated risk of infection. Efficacy results from the independent uptitrated masitinib $6.0 \mathrm{mg} / \mathrm{kg} / \mathrm{d}$ parallel group were inconclusive, and no new safety signal was observed.

\section{Discussion}

Masitinib (4.5 mg/kg/d) can benefit people with PPMS and nSPMS. A confirmatory phase 3 study will be initiated to substantiate these data.

\author{
Correspondence \\ Dr. Vermersch \\ patrick.vermersch@univ-lille.fr
}

MORE ONLINE

III Class of Evidence

Criteria for rating

therapeutic and diagnostic

studies

NPub.org/coe

From the Univ. Lille (P.V.), UMR Inserm U1172, CHU Lille, FHU Precise, France; Neurology Department (L.B.-R.), Hospital Arnau de Vilanova de Lleida, Spain; Mellen Center for Multiple Sclerosis (R.J.F.), Neurological Institute, Cleveland Clinic, OH; Experimental and Clinical Research Center and NeuroCure Clinical Research Center (F.P.), Max Delbrueck Center for Molecular Medicine and Charité Universitaetsmedizin Berlin, corporate member of Freie Universität Berlin, Humboldt-Universität zu Berlin, and Berlin Institute of Health, Germany; Neurology Department (L.R.-T.), Dr Josep Trueta University Hospital, Girona; Neurodegeneration and Neuroinflammation Research Group (L.R.-T.), IDIBGI, Salt; Medical Science Department (L.R.-T.), University of Girona, Spain; Neurology Department (M.S.), Jena University Hospital, Germany; AB Science (A.M., C.M., O.H.), Paris, France; Imagine Institute (O.H.), INSERM UMR 1163, Laboratory of Cellular and Molecular Mechanisms of Hematological Disorders and Therapeutic Implication, Hôpital Necker, Paris, France; and MA LEK AM Maciejowscy SC Centrum Terapii SM (M.M.), Katowice, Poland.

Go to Neurology.org/NN for full disclosures. Funding information is provided at the end of the article.

The Article Processing Charge was funded by the authors.

AB07002 Study Group coinvestigators are listed at links.Iww.com/NXI/A700.

This is an open access article distributed under the terms of the Creative Commons Attribution-NonCommercial-NoDerivatives License 4.0 (CC BY-NC-ND), which permits downloading and sharing the work provided it is properly cited. The work cannot be changed in any way or used commercially without permission from the journal. 


\section{Glossary}

9-HPT = 9-hole peg test $\mathbf{A E}=$ adverse event; ALS = amyotrophic lateral sclerosis; EDSS = Expanded Disability Status Scale; EQ-VAS = Health State Visual Analogue Scale; GEE = generalized estimating equation; HR = hazard ratio; JTR = jump to reference; $\mathbf{L S M}=$ least-squares mean; $\mathbf{m I T T}=$ modified intention to treat; $\mathbf{M S}=$ multiple sclerosis; $\mathbf{M S F C}=$ MS functional composite; MSQOL = MS quality of life; $\mathbf{n S P M S ~ = ~ n o n a c t i v e ~ s e c o n d a r y ~ p r o g r e s s i v e ~ M S ; ~ P A S A T - 3 ~ = ~ P a c e d ~ A u d i t o r y ~ S e r i a l ~}$ Addition Test-3; PPMS = primary progressive MS; SAE = serious nonfatal AE; T25FW = Timed 25-Foot Walk Test.

\section{Trial Registration Information}

The first participant was randomized to study AB07002 on August 25, 2011. The trial was registered with the European Clinical Trials Database (\#EudraCT 2010-021219-17) on July 1, 2011 (clinicaltrialsregister.eu/ctr-search/trial/2010-021219-17/ES) and with ClinicalTrials.gov (\#NCT01433497) on September 14, 2011 (clinicaltrials.gov/ct2/show/NCT01433497).

\section{Classification of Evidence}

This study provides Class II evidence that masitinib $4.5 \mathrm{mg} / \mathrm{kg} / \mathrm{d}$ decreased progression of disability, measured by the EDSS, in adults with PPMS or patients with nSPMS (with no exacerbations in the last 2 years).

Multiple sclerosis (MS) is an inflammatory, demyelinating, and degenerative disease of the CNS. The clinical course of MS is heterogeneous with patients falling into 2 core categories from a pharmacotherapy perspective. ${ }^{1-3}$ The first category, relapsing disease, is associated with processes of inflammatory demyelination, resulting in relapses followed by remissions. The second category, progressive disease, is associated with processes of progressive neurodegeneration resulting in a gradual accrual of neurologic disability. Additional MS phenotype descriptors are based on disease activity (determined by clinical relapses and/or MRI activity) and disease progression (measured by clinical evaluation). ${ }^{4}$ Hence, progressive MS can be described as active and with/without progression or not active and with/without progression.

The vast majority of MS drugs primarily benefit active/relapsing forms of MS with limited efficacy in the progressive forms. This therapeutic divide is consistent with the growing opinion that active/relapsing MS and progressive MS are primarily driven by different disease mechanisms; the former characterized by activity of the peripheral adaptive immune system and the latter by an additional, predominant activity of the innate immune system, compartmentalized within the CNS. ${ }^{5-9}$ Hence, there is an urgent need for innovative drugs that better target the innate immune system and are capable of accumulating within the CNS at sufficient therapeutic concentration.

Clinical proof of concept that masitinib, an oral tyrosine kinase inhibitor, slows disability progression in patients with progressive MS was previously demonstrated in a small phase 2 trial. ${ }^{10,11}$ Masitinib has also demonstrated neuroprotective action in amyotrophic lateral sclerosis (ALS) and Alzheimer disease, via inhibition of microglia, macrophage, and mast cell activity. ${ }^{11-15}$ These are types of innate immune cells that are present in the CNS and are involved in the pathophysiology of progressive MS. ${ }^{16-18}$ Here, we report findings from the phase $3 \mathrm{AB} 07002$ study, the objective of which was to assess whether masitinib can decrease progression of disability, measured by the Expanded Disability Status Scale (EDSS), in adults with primary progressive MS (PPMS) or patients with nonactive secondary progressive MS (nSPMS) (with no exacerbations in the last 2 years).

\section{Methods}

\section{Study Design and Oversight}

Study AB07002 was an international, phase 3, randomized, double-blind, 2 parallel group, placebo-controlled trial over a 96-week treatment period. Patients were randomly assigned $(2: 1)$ to receive masitinib at $4.5 \mathrm{mg} / \mathrm{kg} / \mathrm{d}$ (administered orally as 2 daily intakes) or equivalent placebo. A second, independent parallel group was introduced as an amendment in which patients were randomly assigned $(2: 1)$ to receive masitinib (administered orally as 2 daily intakes) at an initial dose of $4.5 \mathrm{mg} / \mathrm{kg} / \mathrm{d}$ for 12 weeks that was then titrated to a planned dose of $6.0 \mathrm{mg} / \mathrm{kg} / \mathrm{d}$ or equivalent placebo. This amendment effectively replaced a masitinib $6.0 \mathrm{mg} / \mathrm{kg} / \mathrm{d}$ (starting dose) treatment arm, which was terminated following recruitment of 45 patients without analysis, with a lower-risk cohort to improve benefit/risk balance (see eMethods, links. lww.com/NXI/A699). Each parallel group was therefore effectively run as a separate study, distinct in matters of statistical analysis and control arm. Dose reduction or treatment interruption was allowed for moderate or severe safety event according to predefined criteria (see eMethods).

Another notable amendment concerned the primary efficacy analysis, originally defined as MS functional composite (MSFC), which was modified to the EDSS (protocol version 9.0, September 2016, after 19\% [114/611] of patients could have reached the 96-week time point). This was done following issuance of guidance from the European Medicines Agency Committee for Medicinal Products for Human Use, 
stating that the EDSS was the only validated outcome measurement to determine disability in MS and that MSFC should be used as a secondary measurement of disability. ${ }^{19}$

\section{Patients}

Key eligibility criteria were an age of $18-75$ years, MS diagnosis (regardless of time from onset) according to the revised McDonald criteria of PPMS or nSPMS without relapse for at least 2 years prior to inclusion, and a baseline score on the EDSS of 2.0-6.0 inclusive (range, 0 to 10.0 in 0.5-point increments, with higher scores indicating greater disability). ${ }^{2,20}$ In addition, clinical evidence (medical record) of disability progression over the preceding 2 years (as measured by an increase in the EDSS score of at least 1.0 point) was required. The targeted population therefore comprised patients with progressive MS who are progressing but not clinically active (i.e., evidence of disability accumulation over time without relapses). ${ }^{4}$ Key exclusion criteria were concurrent/recent use of immunomodulators, immunosuppressants, interferon beta-1, glatiramer acetate, corticosteroids, or any investigational drug with predefined wash-out periods to avoid potential confounding effects (see eMethods for further details, links.lww.com/NXI/A699).

\section{Outcomes and Statistical Analysis}

Patients were centrally randomized using a computerized central randomization system and minimization method according to the covariates of MS phenotype (PPMS or nSPMS), baseline EDSS score, baseline MSFC subscale scores, and geographical region. Patients and study staff remained masked to treatment assignment for the duration of the study, with site segregation (nonconcurrent recruitment) for the 2 parallel groups. Evaluations were obtained by experienced assessors who were not otherwise involved in patient management. No neuroimaging analyses were included in this protocol.

An estimated 300 patients (200 in the masitinib treatment arm) were required to demonstrate the superiority of masitinib $(4.5 \mathrm{mg} / \mathrm{kg} / \mathrm{d})$ vs placebo for EDSS (repeated-measure analysis including time points from W12 to W96) at a significant level of $5 \%$ for a 2 -sided test and with a power $>80 \%$, based on a difference of means equal to 0.2 points (SD 0.4). The hypothesized response estimates were based on empirical knowledge from phase 2 (AB04011) data, with the same estimate independently applied to the uptitrated $6.0 \mathrm{mg} / \mathrm{kg} / \mathrm{d}$ masitinib parallel group.

Primary efficacy analysis was performed according to a modified intention-to-treat (mITT) data set (i.e., ITT data set minus patients having no intake of drug). The primary end point was change from baseline on the EDSS, calculated using repeatedmeasures methodology (i.e., generalized estimating equation [GEE]) based on all time points measured every 12 weeks over 96 weeks ( $\delta E D S S) ;$ i.e., a population-averaged score comprising 8 consecutive data points from each patient. Note that the EDSS is an ordinal scale and that application of GEE methodology is an established approach for the analysis of ordinal categorical longitudinal data. An advantage of such an approach is that it circumvents many of the limitations associated with mean (single time point) change in the EDSS score from baseline (see the Discussion section). ${ }^{21,22}$ Results were expressed as least-squares mean (LSM) change on the EDSS from baseline ( $\delta$ EDSS, wherein a positive value indicates disability progression), with treatment effect (masitinib vs placebo) reported as the betweengroup difference ( $\Delta \mathrm{LSM}$, wherein a negative value favors masitinib). The change on the EDSS from baseline was calculated using a GEE model with normal distribution and identity link function, $97.04 \%$ CIs, and 2-sided comparison at an overall alpha level of 0.030 (adjusted for a single interim analysis using Pocock alpha spending method, approximated by Hwang-Shih-DeCani function). Missing data were imputed via last observation carried forward methodology for those patients discontinuing before week 96 because of a safety event or lack of efficacy.

Consistency of the primary analysis was tested using predefined sensitivity analyses (EDSS-related secondary endpoints), including change from baseline in ordinal EDSS score averaged for all time points over 96 weeks; a 3-level ordinal EDSS model (GEE [W12-W96]) wherein values of $+1,0$, or -1 were assigned for improved, stable, or worsening condition, respectively. This approach simultaneously measures intrasubject and intragroup incidence of positive and negative outcomes over duration of treatment. A worsening condition was defined as an increase from baseline in the EDSS of $\geq 1.0$ point for a baseline score of $\leq 5.5$ or of $\geq 0.5$ points for a baseline score of $>5.5$ points. Likewise, an improving condition was defined by a decrease from baseline in the EDSS of the aforementioned values. Further additional (missing data) analyses were performed on the primary EDSS and ordinal EDSS end points using a conservative jump-to-reference (JTR) approach, wherein missing data for reason of discontinuation due to lack of efficacy or safety event are imputed using estimates from the control group. ${ }^{23}$ Finally, predefined time-to-event analyses included risk of EDSS progression (first progression and 12-week confirmed) with an additional analysis on risk of progression to an EDSS score of $\geq 7.0$ (representing wheelchair dependency).

Other secondary end points included change from baseline on the MSFC raw scores averaged for all time points over 96 weeks, and its component measures of timed 25 -foot walk test (T25FW, averaged time from 2 tests), 9-hole peg test (9HPT, averaged time from 2 tests on each hand), and Paced Auditory Serial Addition Test-3 (PASAT-3). ${ }^{24}$ Quality of life was measured via change from baseline in the MS quality of life (MSQOL-54) subscales of physical health and mental health and the Health State Visual Analogue Scale (EQ-VAS) (a vertical visual analog scale wherein a score of 0 indicates worst imaginable health and 100 indicates best imaginable health). Similar to the primary analysis, calculations were based on repeated-measures methodology (mixed-effect model repeated measure, timeframe [W12-W96]).

Sensitivity analyses and secondary end points were tested at the 0.05 significance level. Time-to-event analyses were reported as Kaplan-Meier survival estimates with 95\% CIs. All 
Figure 1 Patient Flow Diagram, Detailing Patient Disposition of the Masitinib $4.5 \mathrm{mg} / \mathrm{kg} / \mathrm{d}$ Parallel Group and Uptitrated Masitinib $6.0 \mathrm{mg} / \mathrm{kg} / \mathrm{d}$ Parallel Group

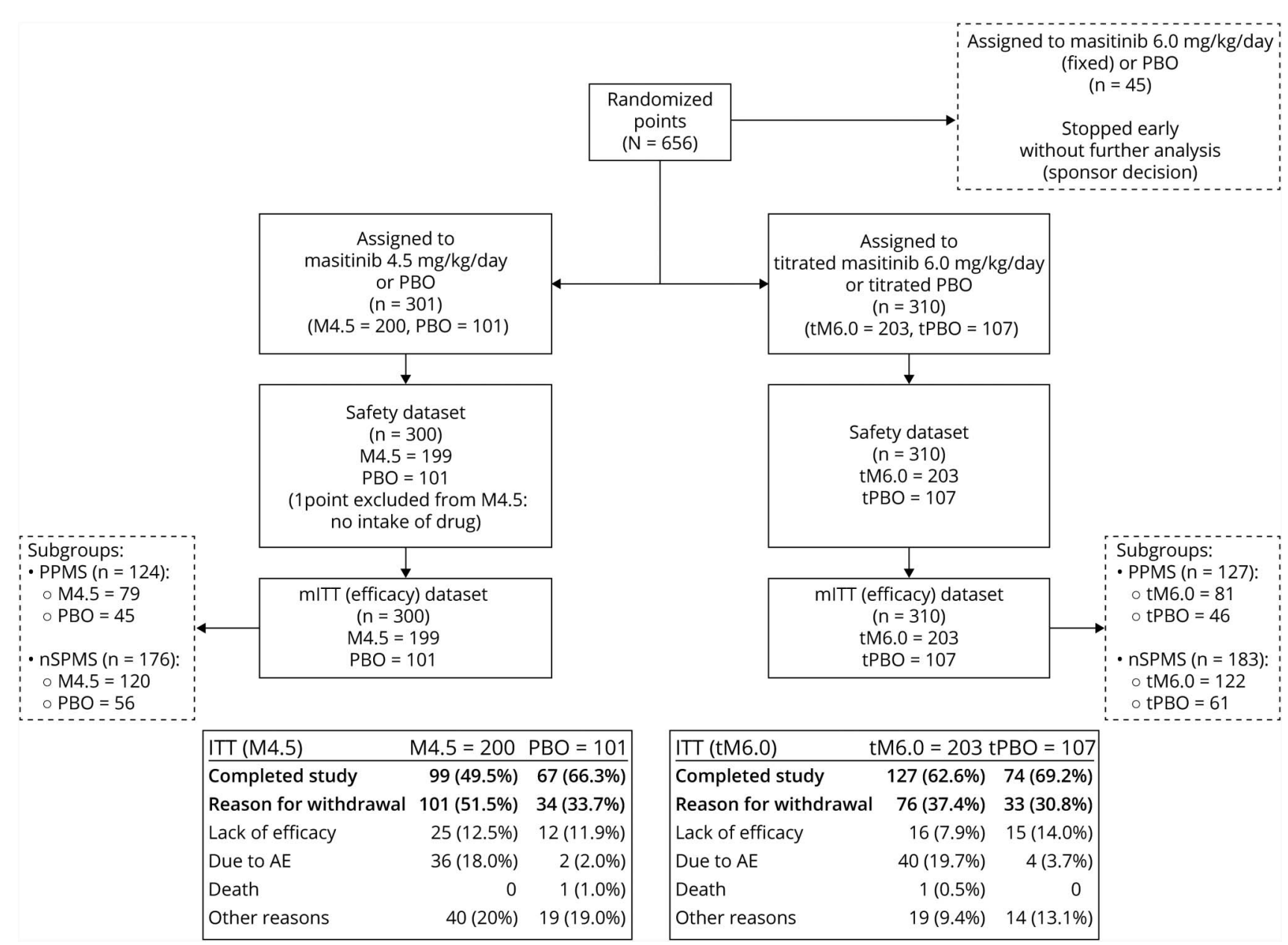

$\mathrm{AE}$ = adverse event; ITT = intention-to-treat data set; M4.5 = masitinib treatment arm from masitinib $4.5 \mathrm{mg} / \mathrm{kg} / \mathrm{d}$ parallel group; $\mathrm{mITT}=\mathrm{modified}$ intention to treat; nSPMS = nonactive secondary progressive multiple sclerosis; PBO = placebo treatment arm from the masitinib $4.5 \mathrm{mg} / \mathrm{kg} / \mathrm{d}$ parallel group; PPMS = primary progressive multiple sclerosis; $\mathrm{tM} 6.0=$ masitinib treatment arm from the titrated $6.0 \mathrm{mg} / \mathrm{kg} / \mathrm{d}$ parallel group; $\mathrm{tPBO}=\mathrm{placebo}$ treatment arm from the titrated $6.0 \mathrm{mg} / \mathrm{kg} / \mathrm{d}$ parallel group.

analyses and reporting procedures were performed using SAS version 9.4 (SAS Institute, Cary, NC).

The safety data set comprised all patients who received at least 1 dose of study medication (Figure 1). Patients were monitored for safety from date of informed consent until 28 days after discontinuing the study drug. Adverse events (AEs) were coded according to the MedDRA dictionary version 20.0.

\section{Standard Protocol Approvals, Registrations, and Patient Consents}

Study AB07002 was designed by the sponsor (AB Science) and independent steering committee members, with study protocol and amendments (see eMethods, links.lww.com/ NXI/A699) approved by relevant institutional review boards or ethics committee at each participating clinical site. The study was overseen by a steering committee, which provided overall supervision and scientific support for the study, and by an independent data safety monitoring committee, which periodically reviewed and evaluated safety data to provide recommendations regarding the patient safety. All patients provided written informed consent. Study AB07002 is registered with Clinicaltrials.gov, number NCT01433497.

\section{Data Availability}

Masitinib is under clinical investigation and has not yet been approved in any sought-after indication by any health authority worldwide. As such, there is no plan for data sharing at this point in time.

\section{Results}

\section{Patients}

From August 2011 through March 2017, a total of 611 patients from 116 hospital clinics and specialized MS centers in 
Table 1 Baseline Patient Characteristics of the Masitinib 4.5 mg/kg/d Parallel Group and Uptitrated Masitinib 6.0 mg/kg/d Parallel Group (ITT Data Sets)

\begin{tabular}{|c|c|c|c|c|}
\hline & \multicolumn{2}{|c|}{ Masitinib $4.5 \mathrm{mg} / \mathrm{kg} / \mathrm{d}$ parallel group } & \multicolumn{2}{|c|}{ Titrated masitinib $6.0 \mathrm{mg} / \mathrm{kg} / \mathrm{d}$ parallel group } \\
\hline & M4.5 $(n=200)$ & PBO $(n=101)$ & tM6.0 $(n=203)$ & tPBO $(n=107)$ \\
\hline Gender (female), \% (n) & $55.5(111)$ & $53.5(54)$ & $60.1(122)$ & $60.7(65)$ \\
\hline \multicolumn{5}{|l|}{ Age, y } \\
\hline Mean \pm SD & $49.8 \pm 9.63$ & $49.7 \pm 10.19$ & $48.6 \pm 10.10$ & $48.8 \pm 9.68$ \\
\hline Range (min-max) & $24-69$ & $25-70$ & $25-70$ & $25-71$ \\
\hline PPMS phenotype, \% (n) & $40(79)$ & $45(45)$ & $39.9(81)$ & $43.0(46)$ \\
\hline \multicolumn{5}{|l|}{ EDSS score } \\
\hline Mean \pm SD & $5.2 \pm 1.07$ & $5.1 \pm 1.06$ & $5.5 \pm 0.95$ & $5.5 \pm 1.01$ \\
\hline Range (min-max) & $2-6$ & $2-6$ & $3-6$ & $2-6$ \\
\hline \multicolumn{5}{|l|}{ EDSS category, \% (n) } \\
\hline 6 & $49.0(98)$ & $47.5(48)$ & $49.3(100)$ & $47.7(51)$ \\
\hline 5 and 5.5 & $20.5(41)$ & $20.8(21)$ & $24.1(49)$ & $19.6(21)$ \\
\hline$<5.5$ & $30.5(61)$ & $31.7(32)$ & $26.6(54)$ & $32.7(35)$ \\
\hline MSFC T25FW, mean \pm SD & $22.8 \pm 31.52$ & $22.7 \pm 37.91$ & $19.2 \pm 24.18$ & $18.8 \pm 24.07$ \\
\hline MSFC 9-HPT, mean \pm SD & $34.0 \pm 18.63$ & $34.2 \pm 20.55$ & $32.9 \pm 14.30$ & $35.1 \pm 25.53$ \\
\hline MSFC PASAT-3, mean \pm SD & $41.6 \pm 13.36$ & $40.1 \pm 14.47$ & $41.9 \pm 13.29$ & $42.2 \pm 12.36$ \\
\hline \multicolumn{5}{|l|}{ Time since MS onset, $y$} \\
\hline Mean \pm SD & $14.0 \pm 9.14$ & $12.6 \pm 7.96$ & $14.2 \pm 9.96$ & $12.5 \pm 8.81$ \\
\hline Range (min-max) & $1-41$ & $2-37$ & $1-47$ & $1-44$ \\
\hline \multicolumn{5}{|l|}{ Time since MS diagnosis, y } \\
\hline Mean \pm SD & $9.1 \pm 7.77$ & $9.0 \pm 8.17$ & $10.0 \pm 8.62$ & $8.3 \pm 8.26$ \\
\hline Range (min-max) & $0-41$ & $0-34$ & $0-43$ & $3-40$ \\
\hline \multicolumn{5}{|l|}{ Region, \% (n) } \\
\hline Poland & $23.0(46)$ & $17.8(18)$ & $40.4(82)$ & $39.3(42)$ \\
\hline Germany/Spain/Ukraine & $48.0(96)$ & $44.6(45)$ & $28.1(57)$ & $29.0(31)$ \\
\hline Rest of the world & $29.0(58)$ & $37.6(38)$ & $31.5(64)$ & $31.8(34)$ \\
\hline
\end{tabular}

Abbreviations: 9-HPT = 9-hole peg test; EDSS = Expanded Disability Status Scale; ITT = intention-to-treat data set; M4.5 = masitinib treatment arm from masitinib $4.5 \mathrm{mg} / \mathrm{kg} / \mathrm{d}$ parallel group; MSFC = multiple sclerosis functional composite; PASAT-3 = Paced Auditory Serial Addition Test-3; PBO = placebo treatment arm from masitinib $4.5 \mathrm{mg} / \mathrm{kg} / \mathrm{d}$ parallel group; PPMS = primary progressive multiple sclerosis; T25FW = timed 25-foot walk test; tM6.0 = masitinib treatment arm from the titrated $6.0 \mathrm{mg} / \mathrm{kg} / \mathrm{d}$ parallel group; $\mathrm{tPBO}=$ placebo treatment arm from the titrated $6.0 \mathrm{mg} / \mathrm{kg} / \mathrm{d}$ parallel group.

20 countries were randomized to study $\mathrm{AB} 07002: 301$ in to the initial parallel group (masitinib dose of $4.5 \mathrm{mg} / \mathrm{kg} / \mathrm{d}$ ) and 310 in to the second parallel group (uptitrated masitinib dose of $6.0 \mathrm{mg} / \mathrm{kg} / \mathrm{d})$.

Considering the masitinib $4.5 \mathrm{mg} / \mathrm{kg} / \mathrm{d}$ parallel group, $1 \mathrm{pa}-$ tient was excluded from the ITT data set because of no study drug intake, yielding safety and mITT data sets of 300 patients each: 101 and 199 patients in the placebo and masitinib treatment arms, respectively. A summary of population disposition for this cohort, including reasons for withdrawal prior to week-96, is described in Figure 1. Randomized patients to this parallel group were similar between treatment arms regarding baseline demographic and clinical characteristics (Table 1). The average age of patients from each treatment arm was approximately 50 years, with about $50 \%$ requiring a walking aid at baseline (EDSS score $\geq 6.0$ ). The average EDSS scores were 5.1 and 5.2 for masitinib and placebo treatment arms, respectively, with patients with PPMS accounting for $40 \%$ and $45 \%$, respectively. Baseline characteristics were also similar among the treatment arms of the PPMS and nSPMS subgroups (eTable 1, links.lww.com/NXI/A699). 
Table 2 Summary of Primary Efficacy End Point and Associated EDSS Sensitivity Analyses for the Masitinib 4.5 mg/kg/d Parallel Group (mITT Data Set)

\begin{tabular}{|c|c|c|c|c|c|}
\hline & PBO $(N=101)$ & M4.5 ( $N=199)$ & Output & Statistic & $p$ Value \\
\hline \multicolumn{6}{|l|}{ Primary analysis } \\
\hline$\delta E D S S$ (SE); repeated-measures EDSS change & $0.098(0.041)$ & $0.001(0.034)$ & $-0.097(-0.192 \text { to }-0.002)^{a}$ & Difference $(97 \% \mathrm{Cl})$ & 0.027 \\
\hline \multicolumn{6}{|l|}{ EDSS sensitivity analyses } \\
\hline 3-level ordinal EDSS model & $\mathrm{n} / \mathrm{a}$ & $\mathrm{n} / \mathrm{a}$ & $0.610(0.376$ to 0.988$)$ & OR $(95 \% \mathrm{Cl})$ & 0.045 \\
\hline $\begin{array}{l}\text { Time-to-first EDSS progression (unconfirmed); events } \\
\text { n (\%) }\end{array}$ & $31(30.7)$ & $34(17.1)$ & $0.58(0.35$ to 0.96$)$ & $\mathrm{HR}(95 \% \mathrm{Cl})$ & 0.034 \\
\hline Time-to-confirmed (12-wk) EDSS progression; events n (\%) & $18(17.8)$ & $22(11.1)$ & $0.63(0.33$ to 1.20$)$ & $\mathrm{HR}(95 \% \mathrm{Cl})$ & 0.159 \\
\hline Time-to-first EDSS score $\geq 7.0$ (unconfirmed); events n (\%) & $6(5.9)$ & $1(0.5)$ & $\mathrm{n} / \mathrm{a}$ & & 0.019 \\
\hline Time-to-confirmed (12-wk) EDSS score $\geq 7.0$; events n (\%) & $4(4.0)$ & $0(0)$ & $\mathrm{n} / \mathrm{a}$ & & 0.013 \\
\hline \multicolumn{6}{|l|}{ EDSS JTR sensitivity analyses } \\
\hline JTR $\delta E D S S$ (SE) & $0.105(0.035)$ & $0.015(0.028)$ & $-0.089(-0.173$ to -0.006$)$ & Difference $(95 \% \mathrm{Cl})$ & 0.037 \\
\hline JTR 3-level ordinal EDSS model & $\mathrm{n} / \mathrm{a}$ & $\mathrm{n} / \mathrm{a}$ & 0.527 (0.274 to 1.012$)$ & OR $(95 \% \mathrm{Cl})$ & 0.054 \\
\hline
\end{tabular}

Abbreviations: EDSS = Expanded Disability Status Scale; HR = hazard ratio; JTR = jump to reference; $\mathrm{mITT}=$ modified intention to treat; $\mathrm{M} 4.5=\mathrm{masitinib}$ treatment arm from masitinib $4.5 \mathrm{mg} / \mathrm{kg} / \mathrm{d}$ parallel group; $\mathrm{n} / \mathrm{a}=$ not applicable; OR = odds ratio; $\mathrm{PBO}=$ placebo treatment arm; SE = standard error; $\delta \mathrm{EDSS}=$ least-squares mean difference in the EDSS (positive value indicates disability progression); $\Delta$ LSM = between-group difference in $\delta E D S S$ (treatment effect; negative value favors masitinib).

This table contains data collected up until the end of the double-blind controlled treatment period as of the clinical cutoff date (November 12, 2019).

${ }^{a} \mathrm{Cl}$ at $97.04 \%$ for primary analysis and at $95 \%$ for all other measures.

Considering the uptitrated masitinib $6.0 \mathrm{mg} / \mathrm{kg} / \mathrm{d}$ parallel group, the ITT and safety data sets each comprised 310 patients: 107 and 203 patients in the placebo and masitinib treatment arms, respectively. A summary of population disposition for this cohort, including reasons for withdrawal prior to week-96, is described in Figure 1. Baseline characteristics were similar among the treatment arms (Table 1). Patients were again enrolled at an advanced stage of the disease (EDSS score $\geq 6.0$ for $49.3 \%$ and $47.7 \%$ of masitinib- and placebotreated patients, respectively), with an average EDSS score of 5.5 for each treatment arm and average age of approximately 49 years. Patients with PPMS accounted for $40 \%$ and $43 \%$ of masitinib and placebo arms, respectively.

\section{Primary Efficacy Analysis}

Masitinib ( $4.5 \mathrm{mg} / \mathrm{kg} / \mathrm{d})$ showed significant benefit over placebo with a $\delta$ EDSS of 0.001 vs 0.098 , respectively, and $\Delta \mathrm{LSM}$ of -0.097 (97\% CI -0.192 to -0.002$) ; p=0.026$ (Table 2). For the masitinib treatment arm, this $\delta$ EDSS value represents a slight worsening in average change of EDSS from baseline over repeated time measures (adjusted for covariates), whereas an increased clinical deterioration in the EDSS was observed for placebo. A sustained treatment effect, indicative of a confirmed between-group difference, was evident from a time series plot of $\delta$ EDSS, measured every 12 weeks over the 96-week treatment period (Figure 2A). For the subgroups of PPMS and nSPMS, the difference in $\triangle \mathrm{LSM}$ was -0.128 (95\% CI -0.285 to -0.028$)$ and -0.104 (95\% CI -0.198 to -0.008$)$, respectively, indicating a comparable treatment effect in both phenotypes.
Results from the second parallel group, with a titrated masitinib dose of $6.0 \mathrm{mg} / \mathrm{kg} / \mathrm{d}$, did not show any significant difference between the masitinib and placebo treatment arms, with a $\delta$ EDSS of 0.009 (SE 0.035) vs -0.005 (SE 0.056), respectively, and $\Delta \mathrm{LSM}$ of +0.014 (97\% CI -0.111 to $+0.140) ; p=0.802$. A time series plot of $\delta$ EDSS, measured every 12 weeks over the 96 -week treatment period, shows that in the PPMS subgroup, the placebo arm exhibited an atypical pattern of EDSS improvement relative to baseline during the early phase of the study (Figure 2B).

\section{Sensitivity Analyses on the EDSS for the Masitinib 4.5 mg/kg/d Parallel Group}

Considering only the masitinib $4.5 \mathrm{mg} / \mathrm{kg} / \mathrm{d}$ parallel group, sensitivity analyses on the EDSS were mostly convergent with the primary end point result, showing a significant advantage for masitinib $4.5 \mathrm{mg} / \mathrm{kg} / \mathrm{d}$ relative to placebo (Table 2). For example, JTR sensitivity analysis for the primary end point gave a significant $\Delta \mathrm{LSM}$ of -0.089 ( $95 \% \mathrm{CI}-0.173$ to -0.006 ; $p=0.037)$. Likewise, the predefined ordinal EDSS score analysis showed that patients receiving masitinib had a significant 39\% increased probability of having either disease improvement or an absence of disease progression relative to placebo (OR 0.610, 95\% CI 0.376-0.988; $p=0.045$ ). For the PPMS subgroup, there was a relative risk reduction of $38 \%$ (OR 0.618, 95\% CI 0.311-1.226), and for the nSPMS subgroup, there was a relative risk reduction of $50 \%$ (OR 0.504, 95\% CI 0.251-1.012). JTR sensitivity analysis on the ordinal EDSS score showed a $47 \%$ increased probability of having either disease improvement or an absence of disease 


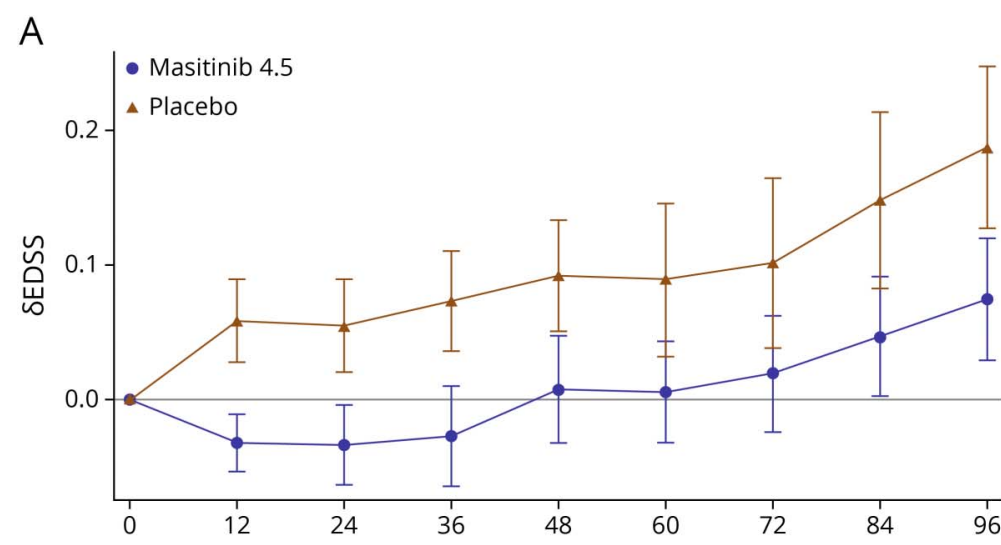

$\mathrm{B}$

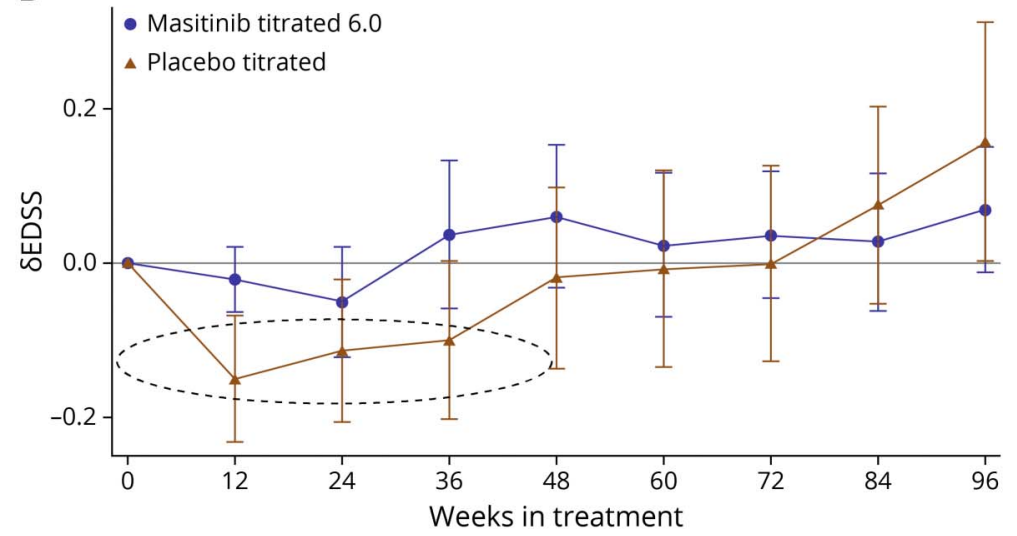

Least-squares mean difference in the EDSS from baseline $(\delta E D S S) \pm S E$, measured every 12 weeks over the 96-week treatment period. (A) Masitinib $4.5 \mathrm{mg} / \mathrm{kg} / \mathrm{d}$ parallel group, $\mathrm{mITT}$. (B) PPMS subgroup of the masitinib titrated $6.0 \mathrm{mg} / \mathrm{kg} /$ $\mathrm{d}$ parallel group PPMS subgroup (the dotted region indicates placebo arm's atypical pattern of EDSS improvement relative to baseline during the early phase of the study). EDSS = Expanded Disability Status Scale; $\delta E D S S$ = least-squares mean difference in the EDSS (positive value indicates disability progression); $\mathrm{mITT}=$ modified intention-to-treat population; PPMS = primary progressive multiple sclerosis. progression in favor of masitinib (OR 0.527, 95\% CI $0.274-1.012 ; p=0.054)$.

The percentage of patients with first EDSS progression was $17.1 \%$ (34/199) for masitinib ( $4.5 \mathrm{mg} / \mathrm{kg} / \mathrm{d})$ vs $30.7 \%$ (31/ 101) for placebo over a timeframe of 96 weeks, corresponding to a significant $42 \%$ risk reduction with masitinib (hazard ratio [HR] 0.58, 95\% CI 0.35-0.96; $p=0.034$ ) (Figure 3). The percentage of patients with 12-week confirmed EDSS progression was $11.1 \%$ (22/199) for masitinib vs $17.8 \%$ (18/101) for placebo over a timeframe of 96 weeks, corresponding to a risk reduction of $37 \%$ with masitinib (HR 0.63, 95\% CI $0.33-1.20 ; p=0.159$ ) (Figure 3 ). Masitinib also significantly reduced the risk of progression to an EDSS score $\geq 7.0$ (12week confirmed), with no patients (0\%) progressing to this stage over 96 weeks in the masitinib treatment arm vs 4 patients $(4 \%)$ in the placebo arm $(p=0.013)$ (eFigure 1 , links. lww.com/NXI/A699). Sensitivity analyses and secondary end point analyses on the titrated masitinib $6.0 \mathrm{mg} / \mathrm{kg} / \mathrm{d}$ data set were not performed because, in accordance to protocol, the primary end point was not met for this parallel group.

\section{Secondary End Point Analyses for the Masitinib 4.5 mg/kg/d Parallel Group}

Considering only the masitinib $4.5 \mathrm{mg} / \mathrm{kg} / \mathrm{d}$ parallel group, a significant difference in change from baseline of 9-HPT (mixed-effect model repeated measures) was seen for masitinib relative to placebo $(p=0.039)$, whereas there was a trend difference for EQ-VAS ( $p=0.075$ ) (eTable 2, links.lww.com/NXI/ A699). However, the majority of secondary end points did not show any discernible effect between arms, including the MSFC score $(p=0.729)$, T25W $(p=0.385)$, PASAT-3 $(p=0.381)$, SQOL-physical health $(p=0.823)$, and MSQOL-mental health $(p=0.578)$.

Further consideration of subgroups showed that the positive secondary end point results were driven by a significant improvement for masitinib $(4.5 \mathrm{mg} / \mathrm{kg} / \mathrm{d})$ in patients with nSPMS; 9-HPT had a $\Delta$ LSM of -5.442 (95\% CI -10.030 to $-0.854 ; p=0.0204)$ and EQ-VAS had a $\Delta$ LSM of 3.59 (95\% CI 0.375-6.814; $p=0.029$ ) (eTable 2, links. lww.com/NXI/A699). A sustained trend in the nSPMS subgroup treatment effect was also evident from a time series analyses of secondary endpoints, measured every 12 weeks over the 96-week treatment period (eTable 3, links. lww.com/NXI/A699).

\section{Safety Analysis for the Masitinib $4.5 \mathrm{mg} / \mathrm{kg} / \mathrm{d}$ Parallel Group}

The incidence of AEs was 94.5\% (188/199) for masitinib (4.5 $\mathrm{mg} / \mathrm{kg} / \mathrm{d}$ ) vs $87.1 \%(88 / 101)$ for placebo (Table 3$)$. AEs (MedDRA preferred terms, regardless of severity) that 
Figure 3 Kaplan-Meier Plot Showing Cumulative Probability of Reaching EDSS Progression for Masitinib 4.5 mg/kg/d (Solid Line) vs Placebo (Dashed Line)

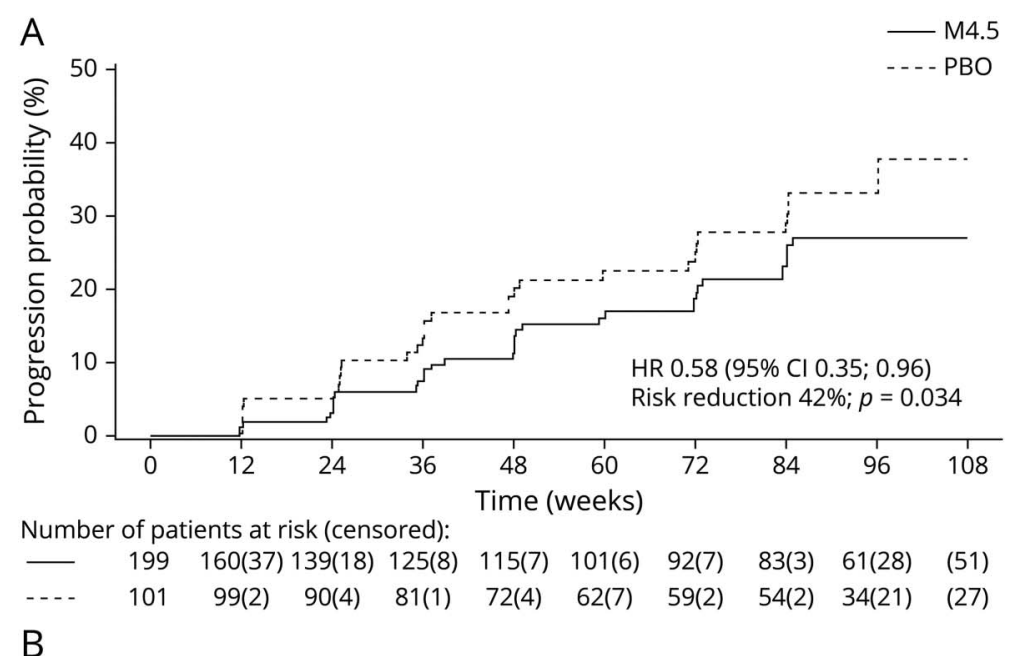

$\mathrm{B}$

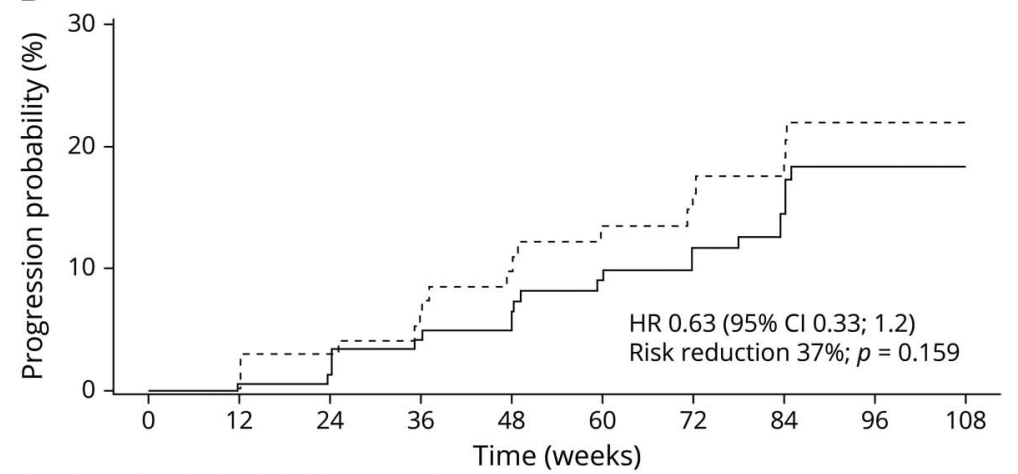

Number of patients at risk (censored):

\begin{tabular}{|c|c|c|c|c|c|c|c|c|}
\hline 199 & $161(37)$ & $140(20)$ & $127(9)$ & 119(8) & $107(6)$ & $98(7)$ & $90(4)$ & $65(31)$ \\
\hline 101 & $99(2)$ & $91(5)$ & $84(4)$ & $76(5)$ & $65(8)$ & $62(2)$ & $57(3)$ & $35(24)$ \\
\hline
\end{tabular}

(A) Risk of first EDSS progression (unconfirmed), showing a risk reduction of $42 \%$ with masitinib. (B) Risk of confirmed EDSS progression (12 weeks), showing a risk reduction of $37 \%$ with masitinib. EDSS = Expanded Disability Status Scale; $\mathrm{HR}=$ hazard ratio; M4.5 = masitinib $4.5 \mathrm{mg} / \mathrm{kg} / \mathrm{d} ; \mathrm{PBO}=$ placebo.

differed by $\geq 5 \%$ in incidence between treatment groups are presented in eTable 4 (links.lww.com/NXI/A699). Those occurring more commonly for masitinib compared with placebo were diarrhea, maculopapular rash, nausea/vomiting, peripheral edema, pruritus, and various laboratory assessments. MS relapses were reported as an AE (by preferred term) with an incidence of $7.5 \%$ (15/199) for masitinib vs $6.9 \%(7 / 101)$ for placebo.

Table 3 Safety Summary of Treatment-Emergent AEs Over the 96-Week Treatment Period (Safety Data Sets, Regardless of Causality)

\begin{tabular}{|c|c|c|c|c|}
\hline \multirow[b]{2}{*}{ Patients with $\geq 1$ event, $\%$ (n) } & \multicolumn{2}{|c|}{ Masitinib 4.5 mg/kg/d parallel group } & \multicolumn{2}{|c|}{ Titrated masitinib $6.0 \mathrm{mg} / \mathrm{kg} / \mathrm{d}$ parallel group } \\
\hline & M4.5 (N = 199) & PBO $(N=101)$ & tM6.0 $(N=203)$ & tPBO $(N=107)$ \\
\hline AE (any grade) & $94.5(188)$ & $87.1(88)$ & $90.6(184)$ & $78.5(84)$ \\
\hline AE leading to death ${ }^{a}$ & 0 & $2.0(2)$ & $1.0(2)$ & 0 \\
\hline Serious AE (nonfatal) & $21.1(42)$ & $12.9(13)$ & $23.2(47)$ & $10.3(11)$ \\
\hline Serious AE (including death) & $21.1(42)$ & $14.9(15)$ & $24.2(49)$ & $10.3(11)$ \\
\hline AE permanent discontinuation ${ }^{b}$ & $20.6(41)$ & $2.0(2)$ & $21.2(43)$ & $8.4(9)$ \\
\hline
\end{tabular}

Abbreviations: $\mathrm{AE}=$ adverse event; M4.5 = masitinib treatment arm from masitinib $4.5 \mathrm{mg} / \mathrm{kg} / \mathrm{d}$ parallel group; PBO = placebo treatment arm from masitinib $4.5 \mathrm{mg} / \mathrm{kg} / \mathrm{d}$ parallel group; tM6.0 = masitinib treatment arm from the titrated $6.0 \mathrm{mg} / \mathrm{kg} / \mathrm{d}$ parallel group; tPBO = placebo treatment arm from the titrated 6.0 $\mathrm{mg} / \mathrm{kg} / \mathrm{d}$ parallel group.

${ }^{a}$ AEs were recorded until 28 days after treatment interruption with any AE not resolved at the death of the patients recorded as an AE leading to death.

${ }^{\mathrm{b}} \mathrm{AE}$ leading to permanent discontinuation excluding death. Safety data set excluded 1 patient from ITT because of no intake of study drug. 
The rate of serious nonfatal AE (SAE) was 21.1\% (42/199) for masitinib vs $12.9 \%$ (13/101) for placebo. The most common treatment-emergent SAEs for masitinib (with an incidence $\geq 1.0 \%$ ), were maculopapular rash, erythema multiforme, elevated gamma-glutamyl transferase, neutropenia, and palmar-plantar erythrodysesthesia syndrome (eTable 5, links.lww.com/NXI/ A699). The 2 cases of erythema multiforme were of moderate severity that resolved without sequelae following discontinuation. No death was reported in the masitinib treatment arm (Table 3).

Patient discontinuation before week 96 was similar between treatment arms for reasons categorized as missing at random ( $21.1 \%$ for masitinib vs $20.8 \%$ for placebo) and due to lack of efficacy ( $12.6 \%$ vs $11.9 \%$, respectively) (Table 4 ). Discontinuations due to $\mathrm{AE}$ were however more frequent in the masitinib treatment arm ( $16.5 \%$ vs $1.0 \%$, respectively); of which for masitinib, 6/33 (18\%) and 14/33 (42\%) were, respectively, based on investigator decision or patient decision due to nonsevere $\mathrm{AE}$, and $4 / 33$ (12\%) patients were discontinued by the investigator in violation of safety protocol rules (i.e., discontinued treatment when protocol proposed dose reduction). Hence, more than $70 \%$ of those discontinuations were attributed to AEs that can be efficiently managed by dose reduction or temporary interruption.

Assessment according to clinical evidence of infections and infestations showed an overall incidence (regardless of severity) of $36.7 \%(73 / 199)$ for masitinib vs $35.6 \%$ (36/101) for placebo (eTable 6, links.lww.com/NXI/A699). Rates according to anatomical site (e.g., upper respiratory tract, lower respiratory tract, and lower urinary tract) were well balanced between treatment arms, as was distribution of severity within each category. The only infectious complication reported as a SAE was urinary tract infection with an incidence of $1.0 \%$ in each treatment arm (2/ 199 vs $1 / 101$, respectively) (eTable 5). Hence, there was no evidence of elevated risk of infection for masitinib relative to placebo over the 96-week treatment period.

\section{Safety Analysis for the Uptitrated Masitinib 6.0 $\mathrm{mg} / \mathrm{kg} / \mathrm{d}$ Parallel Group}

The incidence of treatment-emergent $\mathrm{AE}$ and SAE for masitinib (titrated $6.0 \mathrm{mg} / \mathrm{kg} / \mathrm{d}$ ) was, respectively, 90.6\% (184/203) and $23.2 \%(47 / 203)$ vs $78.5 \%(84 / 107)$ and $10.3 \%(11 / 107)$ for placebo (Table 3). The most common treatment-emergent $\mathrm{AE}$ for masitinib was nausea with an incidence of $11.3 \%$ (23/ 203) vs $2.8 \%(3 / 107)$ for placebo. The most common treatment-emergent SAEs for masitinib were neutropenia (2\%, $4 / 203)$ and maculopapular rash $(2 \%, 4 / 203)$, with neither occurring in the placebo arm. During the study, there were 2 deaths $(1 \%)$ in the masitinib titrated $6.0 \mathrm{mg} / \mathrm{kg} / \mathrm{d}$ group (cellulitis and myocardial infarction) vs none for placebo.

\section{Discussion}

Efficacy results from study $\mathrm{AB07002}$ (as measured using the EDSS, the gold standard instrument for monitoring MS
Table 4 Summary of Reason for Premature Discontinuation for the Masitinib $4.5 \mathrm{mg} / \mathrm{kg} / \mathrm{d}$ Parallel Group; Number (\%) of Patients

\begin{tabular}{|c|c|c|c|}
\hline $\begin{array}{l}\text { Category of } \\
\text { discontinuation }\end{array}$ & Reason & $\begin{array}{l}\text { M4.5 } \\
(n=200)\end{array}$ & $\begin{array}{l}\text { PBO } \\
(n=101)\end{array}$ \\
\hline Total & Any reason & $100(50.0)$ & $34(33.7)$ \\
\hline \multicolumn{4}{|l|}{ MAR } \\
\hline & Total MAR & $42(21.0)$ & $21(20.8)$ \\
\hline & Cancer & $2(1.0)$ & 0 \\
\hline & Death & 0 & $1(1.0)$ \\
\hline & $\begin{array}{l}\text { Eligibility criteria } \\
\text { mistake }\end{array}$ & $2(1.0)$ & 0 \\
\hline & Lost to follow-up & $1(0.5)$ & $1(1.0)$ \\
\hline & Not related TEAE & $3(1.5)$ & $1(1.0)$ \\
\hline & Procedures & $7(3.5)$ & $6(5.9)$ \\
\hline & $\begin{array}{l}\text { Protocol non } \\
\text { compliance }\end{array}$ & $2(1.0)$ & $1(1.0)$ \\
\hline & $\begin{array}{l}\text { Regulatory } \\
\text { suspension }\end{array}$ & $8(4.0)$ & $3(3.0)$ \\
\hline & Travel & $12(6.0)$ & $4(4.0)$ \\
\hline & Unknown & $5(2.5)$ & $4(4.0)$ \\
\hline \multicolumn{4}{|l|}{ MNAR } \\
\hline & Total MNAR & $58(29.0)$ & $13(12.9)$ \\
\hline & Lack of efficacy & $25(12.5)$ & 12 (11.9) \\
\hline & Drug-related TEAE & $33(16.5)$ & $1(1.0)$ \\
\hline
\end{tabular}

Drug-related TEAE

breakdown

\begin{tabular}{cll}
\hline Investigator decision $^{\mathrm{a}}$ & $14(7.0)$ & 0 \\
\hline Severe & $8(4.0)$ & 0 \\
\hline Moderate & $6(3.0)$ & 0 \\
\hline Mild & 0 & 0 \\
\hline Safety rule violation $^{\mathrm{b}}$ & $4(2.0)$ & 0 \\
\hline Severe & 0 & 0 \\
\hline Moderate & $3(1.5)$ & 0 \\
\hline Mild & $1(0.5)$ & 0 \\
\hline Patient decision & $15(7.5)$ & $1(1.0)$ \\
\hline Severe & $1(0.5)$ & 0 \\
\hline Moderate & $12(6.0)$ & $1(1.0)$ \\
\hline Mild & $2(1.0)$ & 0 \\
\hline
\end{tabular}

Abbreviations: $\mathrm{M} 4.5$ = masitinib $4.5 \mathrm{mg} / \mathrm{kg} / \mathrm{d} ; \mathrm{MAR}=$ missing at random; $\mathrm{MNAR}=$ missing not at random; $\mathrm{PBO}=$ placebo; $\mathrm{TEAE}=$ treatment-emergent adverse event.

a Discontinuation based on investigator decision as per protocol safety rules.

${ }^{b}$ Discontinuation based on investigator decision that was in violation of protocol safety rules and could have been managed without need to discontinue. Adverse events described using MedDRA preferred terms. 
disease severity) significantly favored masitinib $(4.5 \mathrm{mg} / \mathrm{kg} /$ d) over placebo. The observed primary end point treatment effect is supported by convergence in EDSS sensitivity analyses. Moreover, benefit was demonstrated in a relatively diverse population that comprised both PPMS and nSPMS subgroups.

Conversely, results from the uptitrated masitinib $6.0 \mathrm{mg} / \mathrm{kg} / \mathrm{d}$ parallel group did not demonstrate any treatment effect. This was unexpected, the experience of masitinib in another neurodegenerative indication that also targeted mast cell and microglia activity (i.e., ALS) having indicated possible dosedependent efficacy. ${ }^{12}$ One explanation for this divergent result is that the titrated $6.0 \mathrm{mg} / \mathrm{kg} / \mathrm{d}$ parallel group placebo arm had an atypical pattern of EDSS improvement relative to baseline during the early phase of the study (Figure 2B), which then compromised all subsequent analysis and resulted in an implausible situation of the placebo arm showing an overall improvement relative to baseline after 96 weeks. What we can infer from these data, however, is that in terms of benefit/risk balance, the recommended masitinib dose for future development should be $4.5 \mathrm{mg} / \mathrm{kg} / \mathrm{d}$. This is based on an apparent absence of the dose-dependent treatment effect, as evidenced by similar EDSS time series profiles (i.e., rate of change in the EDSS over 96 weeks) for the masitinib $4.5 \mathrm{mg} / \mathrm{kg} / \mathrm{d}$ and titrated masitinib $6.0 \mathrm{mg} / \mathrm{kg} / \mathrm{d}$ treatment arms (Figure 2, A and B, respectively) and because of a more favorable safety profile for the masitinib $4.5 \mathrm{mg} / \mathrm{kg} / \mathrm{d}$ cohort (Table 3 ).

An innovative design feature of study AB07002 is its use of EDSS repeated-measures GEE methodology for the primary efficacy outcome, as opposed to survival or disability progression analyses that consider a specific milestone. ${ }^{25}$ The latter approaches ignore available data, both before and after reaching the milestone, do not consider differences between individual trajectories, and have a relatively low incidence of milestone attainment over 2 years in the placebo group. Conversely, GEE repeated-measure models, where observations are clustered within individuals, use all available information to generate a population-averaged interpretation of the data, which takes into account the fluctuating nature of EDSS over time (i.e., all detectable improvement and worsening). Furthermore, this approach accounts for time variation and the correlations between repeated measurements found in a longitudinal study design and is relatively insensitive to within and between patient EDSS measurement variability (i.e., due to missing data or investigator variability). Another advantage of this end point is a reduced sample size requirement for a given study power as compared with the conventional time to confirmed disability progression end point, although this gain comes at the expense of those secondary end points being underpowered. One potential caveat to this approach, however, is that there is no precedent for its use in other MS trials and that the numeric values associated with $\delta$ EDSS (which is now effectively an interval scale) are not relatable to the original EDSS scores or intervals (which is an ordinal scale), making direct clinical interpretation more challenging.
Overall, safety results from this study were consistent with the known profile for masitinib (e.g., diarrhea, rash, nausea, peripheral edema, pruritus, and dyspepsia), and there were no new safety concerns. ${ }^{12,26}$ There was no evidence of increased risk of infection with masitinib, which could prove advantageous compared with other MS drugs, many of which are associated with an increased risk of infectious complications both in terms of frequency (e.g., increased rates of minor infections) and severity (e.g., potentially life-threatening opportunistic infections such as progressive multifocal leukoencephalopathy). ${ }^{27,28}$

The only drug currently approved for treatment of PPMS is ocrelizumab, a humanized monoclonal antibody targeting the CD20 antigen on B cells, for which a single pivotal trial was conducted in PPMS, whereas there is no accepted drug for nSPMS (siponimod being approved solely for relapsing/active SPMS). ${ }^{29-31}$ Comparison between masitinib AB07002 results and other treatments for progressive MS is complicated by important differences in study design, patient inclusion criteria, primary end points used, and pharmacologic action. For example, ocrelizumab is approved for treatment of patients with PPMS with active disease (imaging features characteristic of active inflammation at baseline) and early disease in terms of disease duration and level of disability (i.e., younger patients less than 45 years of age), as reflected in the indication approved by regulatory authorities. ${ }^{32}$ In contrast, the positive results from masitinib study $\mathrm{AB} 07002$ are in the context of a broader population with little restriction on age, no restriction on duration of disease, and targeting patients with progressive MS (both PPMS and SPMS) who are progressing but are not clinically active.

Mechanistic implications of masitinib's dual action against activated cells of the neuroimmune system may influence the future direction of drug development in progressive MS; for example, by prompting a move away from immunomodulating agents that predominantly target B-cell and T-cell signaling pathways or a combined therapeutic approach that targets both the peripheral adaptive and CNS innate immune systems. These positive clinical findings also provide compelling evidence implicating mast cells and/or macrophage/microglia to the pathophysiology of truly progressive MS. However, further preclinical studies are needed to better understand how masitinib's observed therapeutic benefit is attributable to inhibition of macrophage, microglia, and mast cell activity; for example, testing the hypothesis that masitinib is capable of switching the neuroimmune system from a neurotoxic state toward a neuroprotective state with resultant remodeling of the neuronal microenvironment. ${ }^{33}$ Indeed, neuroprotection associated with masitinib's therapeutic targeting of these cells in other neurodegenerative disorders suggests that reduction of neuronal damage in MS is also probable. ${ }^{13,15}$

In conclusion, masitinib at $4.5 \mathrm{mg} / \mathrm{kg} / \mathrm{d}$ can benefit patients by slowing EDSS-based disability worsening; however, validation of these findings via a confirmatory phase 3 study will be necessary, in part because neuroimaging data were not collected during the current study and also due to an absence of signal on secondary end points. Overall, study AB07002 
represents the first successful randomized, controlled, phase 3 trial in progressive MS of a tyrosine kinase inhibitor, targeting innate immune cells.

\section{Acknowledgment}

The authors thank the study participants, their families, and caregivers. They also thank the AB07002 Study Group Investigators.

\section{Study Funding}

This study was supported by AB Science, Paris, France.

\section{Disclosure}

Masitinib is under clinical development by the study funder, AB Science. P. Vermersch reports research support and/or personal fees from Biogen, Sanofi Genzyme, Novartis, Teva, Merck, Roche, Celgene and Imcyse. L. Brieva-Ruiz reports personal fees from Bayer, Celgene, Biogen, Genzyme, Merck, Novartis, Roche, Almirall, and Teva. R.J. Fox reports personal fees from $\mathrm{AB}$ Science, Actelion, Biogen, Celgene, EMD Serono, Genentech, Immunic, Novartis, Sanofi, and TG Therapeutics. F. Paul reports research support and/or personal fees from Bayer, Biogen Idec, Merck Serono, Alexion, Guthy Jackson Foundation, Viela Bio, Novartis, Roche, Sanofi Genzyme, Mitsubishi Tanabe, and UCB. L. Ramio-Torrenta reports personal fees and/or nonfinancial support from Biogen, Merck, Sanofi, Roche, Bristol Myers, Almirall, Novartis, and Teva. M. Schwab reports no competing interests. A. Moussy, C. Mansfield, and O. Hermine are employees and shareholders of AB Science. M. Maciejowski reports personal fees from Biogen, Novartis, Roche, Merck, and Bayer. Go to Neurology.org/NN for full disclosures.

\section{Publication History}

Received by Neurology: Neuroimmunology \& Neuroinflammation September 1, 2021. Accepted in final form January 12, 2022. Submitted and externally peer reviewed. The handling editor was Scott S. Zamvil, MD, PhD, FAAN.

Appendix 1 Authors

\begin{tabular}{lll}
\hline Name & Location & Contribution \\
\hline $\begin{array}{l}\text { Patrick } \\
\text { Vermersch, } \\
\text { MD, PhD }\end{array}$ & $\begin{array}{l}\text { Univ. Lille, UMR Inserm } \\
\text { Precise, France }\end{array}$ & $\begin{array}{l}\text { Drafting/revision of the } \\
\text { manuscript for content, } \\
\text { including medical writing for } \\
\text { content; major role in the } \\
\text { acquisition of data; study } \\
\text { concept or design; and analysis } \\
\text { or interpretation of data }\end{array}$ \\
\hline $\begin{array}{l}\text { Luis Brieva- } \\
\text { Ruiz, MD }\end{array}$ & $\begin{array}{l}\text { Neurology Department, } \\
\text { Hospital Arnau de Vilanova } \\
\text { de Lleida, Spain }\end{array}$ & $\begin{array}{l}\text { Drafting/revision of the } \\
\text { manuscript for content, } \\
\text { including medical writing for }\end{array}$ \\
& $\begin{array}{l}\text { content, and major role in } \\
\text { the acquisition of data }\end{array}$ \\
\hline $\begin{array}{l}\text { Robert J. Fox, } \\
\text { MD }\end{array}$ & $\begin{array}{l}\text { Mellen Center for Multiple } \\
\text { Sclerosis, Neurological } \\
\text { Institute, Cleveland Clinic, } \\
\text { OH }\end{array}$ & $\begin{array}{l}\text { Drafting/revision of the } \\
\text { manuscript for content, } \\
\text { including medical writing for } \\
\text { content, and analysis or } \\
\text { interpretation of data }\end{array}$
\end{tabular}

Appendix 1 (continued)

\begin{tabular}{|c|c|c|}
\hline Name & Location & Contribution \\
\hline $\begin{array}{l}\text { Friedemann } \\
\text { Paul, MD, } \\
\text { PhD }\end{array}$ & $\begin{array}{l}\text { Experimental and Clinical } \\
\text { Research Center and } \\
\text { NeuroCure Clinical Research } \\
\text { Center, Max Delbrueck } \\
\text { Center for Molecular } \\
\text { Medicine and Charité } \\
\text { Universitaetsmedizin Berlin, } \\
\text { corporate member of Freie } \\
\text { Universität Berlin, } \\
\text { Humboldt-Universität zu } \\
\text { Berlin, and Berlin Institute of } \\
\text { Health, Germany }\end{array}$ & $\begin{array}{l}\text { Drafting/revision of the } \\
\text { manuscript for content, } \\
\text { including medical writing for } \\
\text { content, and analysis or } \\
\text { interpretation of data }\end{array}$ \\
\hline $\begin{array}{l}\text { Lluis Ramio- } \\
\text { Torrenta, } \\
\text { MD, PhD }\end{array}$ & $\begin{array}{l}\text { Neurology Department, Dr } \\
\text { Josep Trueta University } \\
\text { Hospital, Girona; } \\
\text { Neurodegeneration and } \\
\text { Neuroinflammation } \\
\text { Research Group, IDIBGI, } \\
\text { Salt; Medical Science } \\
\text { Department, University of } \\
\text { Girona, Spain }\end{array}$ & $\begin{array}{l}\text { Drafting/revision of the } \\
\text { manuscript for content, } \\
\text { including medical writing for } \\
\text { content, and major role in } \\
\text { the acquisition of data }\end{array}$ \\
\hline $\begin{array}{l}\text { Matthias } \\
\text { Schwab, MD, } \\
\text { PhD }\end{array}$ & $\begin{array}{l}\text { Neurology Department, } \\
\text { Jena University Hospital, } \\
\text { Germany }\end{array}$ & $\begin{array}{l}\text { Drafting/revision of the } \\
\text { manuscript for content, } \\
\text { including medical writing for } \\
\text { content, and major role in } \\
\text { the acquisition of data }\end{array}$ \\
\hline $\begin{array}{l}\text { Alain } \\
\text { Moussy, } \\
\text { MEng }\end{array}$ & AB Science, Paris, France & $\begin{array}{l}\text { Drafting/revision of the } \\
\text { manuscript for content, } \\
\text { including medical writing for } \\
\text { content; study concept or } \\
\text { design; and analysis or } \\
\text { interpretation of data }\end{array}$ \\
\hline $\begin{array}{l}\text { Colin } \\
\text { Mansfield, } \\
\text { PhD }\end{array}$ & AB Science, Paris, France & $\begin{array}{l}\text { Drafting/revision of the } \\
\text { manuscript for content, } \\
\text { including medical writing for } \\
\text { content, and analysis or } \\
\text { interpretation of data }\end{array}$ \\
\hline $\begin{array}{l}\text { Olivier } \\
\text { Hermine, } \\
\text { MD, PhD }\end{array}$ & $\begin{array}{l}\text { AB Science, Paris, France; } \\
\text { Imagine Institute, INSERM } \\
\text { UMR 1163, Laboratory of } \\
\text { Cellular and Molecular } \\
\text { Mechanisms of } \\
\text { Hematological Disorders } \\
\text { and Therapeutic } \\
\text { Implication, Hôpital Necker, } \\
\text { Paris, France }\end{array}$ & $\begin{array}{l}\text { Drafting/revision of the } \\
\text { manuscript for content, } \\
\text { including medical writing for } \\
\text { content; study concept or } \\
\text { design; and analysis or } \\
\text { interpretation of data }\end{array}$ \\
\hline $\begin{array}{l}\text { Maciej } \\
\text { Maciejowski, } \\
\text { MD, PhD }\end{array}$ & $\begin{array}{l}\text { MA LEK AM Maciejowscy SC } \\
\text { Centrum Terapii SM, } \\
\text { Katowice, Poland }\end{array}$ & $\begin{array}{l}\text { Drafting/revision of the } \\
\text { manuscript for content, } \\
\text { including medical writing for } \\
\text { content, and major role in } \\
\text { the acquisition of data }\end{array}$ \\
\hline
\end{tabular}

\section{Appendix 2 Coinvestigators}

AB07002 Study Group coinvestigators are listed at links.Iww.com/NXI/A700.

\section{References}

1. Lublin FD, Reingold SC. Defining the clinical course of multiple sclerosis: results of an international survey. National Multiple Sclerosis Society (USA) Advisory Committee on Clinical Trials of New Agents in Multiple Sclerosis. Neurology. 1996;46(4): 907-911.

2. Polman $\mathrm{CH}$, Reingold SC, Banwell B, et al. Diagnostic criteria for multiple sclerosis: 2010 revisions to the McDonald criteria. Ann Neurol. 2011;69(2): 292-302. 
3. Krieger SC, Cook K, De Nino S, Fletcher M. The topographical model of multiple sclerosis: a dynamic visualization of disease course. Neurol Neuroimmunol Neuroinflamm. 2016;3(5):e279.

4. Lublin FD, Reingold SC, Cohen JA, et al. Defining the clinical course of multiple sclerosis: the 2013 revisions. Neurology. 2014;83(3):278-286.

5. Stys PK, Tsutsui S. Recent advances in understanding multiple sclerosis. F1000Res. 2019;8:F1000 Faculty Rev-2100.

6. Hendriksen E, van Bergeijk D, Oosting RS, Redegeld FA. Mast cells in neuroinflammation and brain disorders [published correction appears in Neurosci Biobehav Rev. 2017;83:774]. Neurosci Biobehav Rev. 2017;79:119-133.

7. Fani Maleki A, Rivest S. Innate immune cells: monocytes, monocyte-derived macrophages and microglia as therapeutic targets for Alzheimer's disease and multiple sclerosis. Front Cell Neurosci. 2019;13:355.

8. Skaper SD, Facci L, Zusso M, Giusti P. An inflammation-centric view of neurological disease: beyond the neuron [published correction appears in Front Cell Neurosci. 2020;13:578]. Front Cell Neurosci. 2018;12:72.

9. Skaper SD, Facci L, Giusti P. Mast cells, glia and neuroinflammation: partners in crime? Immunology. 2014;141(3):314-327.

10. Dubreuil P, Letard S, Ciufolini M, et al. Masitinib (AB1010), a potent and selective tyrosine kinase inhibitor targeting KIT. PLoS One. 2009;4(9):e7258.

11. Vermersch P, Benrabah R, Schmidt N, et al. Masitinib treatment in patients with progressive multiple sclerosis: a randomized pilot study. BMC Neurol. 2012;12:36.

12. Mora JS, Genge A, Chio A, et al. Masitinib as an add-on therapy to riluzole in patients with amyotrophic lateral sclerosis: a randomized clinical trial. Amyotroph Lateral Scler Frontotemporal Degener. 2020;21(1-2):5-14.

13. Trias E, Ibarburu S, Barreto-Núñez R, et al. Post-paralysis tyrosine kinase inhibition with masitinib abrogates neuroinflammation and slows disease progression in inherited amyotrophic lateral sclerosis. J Neuroinflammation. 2016;13(1):177.

14. Piette F, Belmin J, Vincent H, et al. Masitinib as an adjunct therapy for mild-tomoderate Alzheimer's disease: a randomised, placebo-controlled phase 2 trial. Alzheimers Res Ther. 2011;3(2):16.

15. Li T, Martin E, Abada YS, et al. Effects of chronic masitinib treatment in APPswe/ PSEN1dE9 transgenic mice modeling Alzheimer's disease. J Alzheimers Dis. 2020; 76(4):1339-1345

16. Brown MA, Weinberg RB. Mast cells and innate lymphoid cells: underappreciated players in CNS autoimmune demyelinating disease. Front Immunol. 2018;9:514.

17. Jones MK, Nair A, Gupta M. Mast cells in neurodegenerative disease. Front Cell Neurosci. 2019;13:171.

18. Luo C, Jian C, Liao Y, et al. The role of microglia in multiple sclerosis. Neuropsychiatr Dis Treat. 2017;13:1661-1667.

19. European Medicines Agency. Guideline on clinical investigation of medicinal products for the treatment of multiple sclerosis. Committee for Medicinal Products for
Human Use (CHMP). EMA/CHMP/771815/2011, Rev. 2. ema.europa.eu/en/ clinical-investigation-medicinal-products-treatment-multiple-sclerosis (accessed 9 September 2020).

20. Kurtzke JF. Rating neurologic impairment in multiple sclerosis: an expanded disability status scale (EDSS). Neurology. 1983;33(11):1444-1452.

21. Lipsitz S, Fitzmaurice G. Generalized estimation equations for longitudinal data analysis. In: Longitudinal Data Analysis. Chapman \& Hall/CRC; 2008:43-78.

22. Pedroza C, Truong VTT. Estimating relative risks in multicenter studies with a small number of centers-which methods to use? A simulation study. Trials. 2017;18(1) 512 .

23. Kenward M. Controlled multiple imputation methods for sensitivity analyses in longitudinal clinical trials with dropout and protocol deviation. Clin Invest. 2015;5: 311-320.

24. Fischer JS, Rudick RA, Cutter GR, Reingold SC. The multiple sclerosis functional composite measure (MSFC): an integrated approach to MS clinical outcome assessment. National MS Society Clinical Outcomes Assessment Task Force. Mult Scler. 1999;5(4):244-250.

25. Meca-Lallana V, Berenguer-Ruiz L, Carreres-Polo J, et al. Deciphering multiple sclerosis progression. Front Neurol. 2021;12:608491.

26. Lortholary O, Chandesris MO, Bulai Livideanu C, et al. Masitinib for treatment of severely symptomatic indolent systemic mastocytosis: a randomised, placebocontrolled, phase 3 study. Lancet. 2017;389(10069):612-620.

27. Zappulo E, Buonomo AR, Saccà F, et al. Incidence and predictive risk factors of infective events in patients with multiple sclerosis treated with agents targeting CD20 and CD52 surface antigens. Open Forum Infect Dis. 2019;6(11) ofz 445 .

28. Chahin S, Berger JR. A risk classification for immunosuppressive treatment-associated progressive multifocal leukoencephalopathy. J Neurovirol. 2015;21(6):623-631.

29. Montalban X, Hauser SL, Kappos L, et al. Ocrelizumab versus placebo in primary progressive multiple sclerosis. $N$ Engl J Med. 2017;376(3):209-220.

30. Kappos L, Bar-Or A, Cree BAC, et al. Siponimod versus placebo in secondary progressive multiple sclerosis (EXPAND): a double-blind, randomised, phase 3 study [published correction appears in Lancet. 2018;392(10160):2170]. Lancet. 2018; 391(10127):1263-1273

31. Gehr S, Kaiser T, Kreutz R, Ludwig WD, Paul F. Suggestions for improving the design of clinical trials in multiple sclerosis-results of a systematic analysis of completed phase III trials. EPMA J. 2019;10(4):425-436.

32. Canadian Agency for Drugs and Technologies in Health (CADTH). Clinical Review Report: Ocrelizumab (Ocrevus): Hoffmann-La Roche Limited. : Canadian Agency for Drugs and Technologies in Health; 2017.

33. Kwon HS, Koh SH. Neuroinflammation in neurodegenerative disorders: the roles of microglia and astrocytes. Transl Neurodegener. 2020;9(1):42 


\title{
Neurology \\ Neuroimmunology \& Neuroinflammation
}

\author{
Efficacy and Safety of Masitinib in Progressive Forms of Multiple Sclerosis: A \\ Randomized, Phase 3, Clinical Trial \\ Patrick Vermersch, Luis Brieva-Ruiz, Robert J. Fox, et al. \\ Neurol Neuroimmunol Neuroinflamm 2022;9; \\ DOI 10.1212/NXI.0000000000001148
}

This information is current as of February 21, 2022

Updated Information \&

Services

References

Subspecialty Collections

Permissions \& Licensing

Reprints including high resolution figures, can be found at:

http://nn.neurology.org/content/9/3/e1148.full.html

This article cites 30 articles, 1 of which you can access for free at: http://nn.neurology.org/content/9/3/e1148.full.html\#\#ref-list-1

This article, along with others on similar topics, appears in the following collection(s):

Class II

http://nn.neurology.org//cgi/collection/class_ii

Clinical trials Randomized controlled (CŌNSORT agreement)

http://nn.neurology.org//cgi/collection/clinical_trials_randomized_cont rolled_consort_agreement

Multiple sclerosis

http://nn.neurology.org//cgi/collection/multiple_sclerosis

Information about reproducing this article in parts (figures,tables) or in its entirety can be found online at:

http://nn.neurology.org/misc/about.xhtml\#permissions

Information about ordering reprints can be found online:

http://nn.neurology.org/misc/addir.xhtml\#reprintsus

Neurol Neuroimmunol Neuroinflamm is an official journal of the American Academy of Neurology.

Published since April 2014, it is an open-access, online-only, continuous publication journal. Copyright

Copyright $\odot 2022$ The Author(s). Published by Wolters Kluwer Health, Inc. on behalf of the American

Academy of Neurology.. All rights reserved. Online ISSN: 2332-7812.

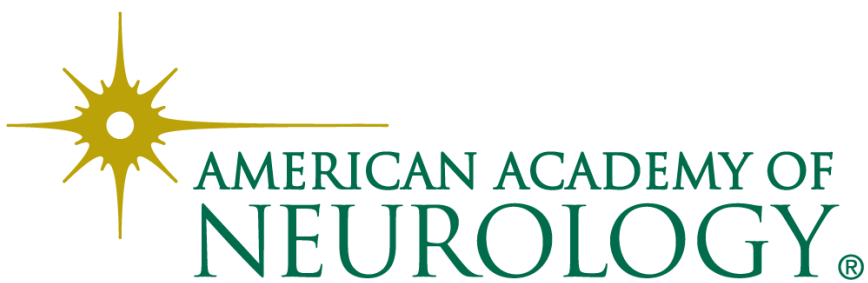

